\title{
EFFECT OF IRON PROPHYLAXIS IN PREVENTING IRON DEFICIENCY ANAEMIA IN TERM INFANTS
}

\author{
Veerendra Kumar Madhavan Nair'1, Balamurugan A. $S^{2}$
}

${ }^{1}$ Associate Professor, Department of Paediatrics, Government Medical College, Parippally, Kerala.

${ }^{2}$ Senior Resident, Department of Paediatrics, Government Medical College, Kottayam, Kerala.

ABSTRACT

\section{BACKGROUND}

Iron deficiency is the most widespread and common nutritional disorder in the world. Anaemia adversely affects the mental and motor development of the infants. Additional sources of iron are needed after about 4 months when neonatal iron stores have been depleted.

Objective - What is the effect of iron prophylaxis in term infants from four-to-six months of age in preventing iron deficiency anaemia at one year of age?

\section{MATERIALS AND METHODS}

It was an experimental study conducted in Well Baby Clinic of a Tertiary Level Hospital in South India, done in a period of one year from February 2015 to July 2016. Study included term infants in the age group of 4 to 6 months without anaemia. All the eligible infants selected for the study were divided into 2 groups. Infants were selected alternatively, first infant who came with the eligible criteria was put in iron supplementation group, next infant in the non-iron supplement (control) group and so on. Initial and final haemoglobin and growth parameters on every review were noted. At one year age, if anaemic, detailed evaluation also done.

\section{RESULTS}

Among 44 infants, proportion of anaemia (after the study) among iron given group was found to be $22.7 \%$ compared to the control group, which was $72.7 \%$. The difference in proportion was found to be statistically significant. The mean of weight difference between supplemented group and control group was also statistically significant.

\section{CONCLUSION}

Prophylactic iron supplementation from 4 to 6 months of age onwards will prevent iron deficiency anaemia, improves haemoglobin level and body weight.

\section{KEYWORDS}

Iron Deficiency, Iron Prophylaxis, Anaemia.

HOW TO CITE THIS ARTICLE: Nair VKM, Balamurugan AS. Effect of iron prophylaxis in preventing iron deficiency anaemia in term infants. J. Evolution Med. Dent. Sci. 2017;6(7):559-561, DOI: 10.14260/Jemds/2017/119

\section{BACKGROUND}

Iron is essential for virtually all living organisms. Iron deficiency is the most widespread and common nutritional disorder in the world. It is estimated that $30 \%$ of the global population suffers from iron-deficiency anaemia and most of them live in developing countries.1,2,3,4

Anaemia in infants is defined as haemoglobin, haematocrit and RBC count less than 2SD for mean age, sex and race. Haemoglobin $<11$, haematocrit $<33$ is considered as anaemia in infants and toddlers. Iron deficiency anaemia is considered when MCV $<70 \mathrm{fl}$, $\mathrm{MCH}<23 \mathrm{pg}, \mathrm{MCHC}<30 \mathrm{~g} \%$ for 6-24 months ${ }^{4}$ and serum ferritin $\leq 12$.

Iron deficiency anaemia in children can be classified as mild - Hb 10 - $10.9 \mathrm{~g} / \mathrm{dL}$, moderate - $\mathrm{Hb} 7$ - $9.9 \mathrm{~g} / \mathrm{dL}$, severe $\mathrm{Hb}<7 \mathrm{~g} / \mathrm{dL}$. Haemoglobin concentration is most often used for anaemia screening in children from 4 months to 1 year.

Financial or Other, Competing Interest: None.

Submission 15-12-2016, Peer Review 09-01-2017,

Acceptance 14-01-2017, Published 23-01-2017.

Corresponding Author:

Dr. Veerendra Kumar Madhavan Nair,

Lekshminivas,

Shasthamkavu,

Karapuzha,

Kottayam West PO - 686003,

Kerala.

E-mail: vkumarbabu@gmail.com

DOI: $10.14260 /$ jemds $/ 2017 / 119$

\section{(c) $(1) \odot$}

Anaemia adversely affects the mental and motor development, and the behaviour of the infants. There is evidence that the developmental deficit occur due to iron deficiency in infancy may be irreversible. 4 Prevention of iron deficiency anaemia in infants and growing children need to be accorded a high priority for improving the quality of life. ${ }^{4}$

In an infant aged 4 to 6 months about $0.6 \mathrm{mg} /$ day is needed for blood growth and growth of muscle and other tissues. The concentration of iron in human milk is low (0.2 $0.4 \mathrm{mg}$ ). An exclusive breast feed in a 4-month-old infant would absorb $0.12 \mathrm{mg}$ of iron daily, this is approximately sufficient for covering the estimated basal iron losses $[0.15$ $\mathrm{mg} /$ day), but there is no net gain of iron.5,6

The body of a full-term newborn infant contains about 0.5 $\mathrm{g}$ of iron compared to $5 \mathrm{~g}$ of iron in adults. ${ }^{4,6}$ Additional sources of iron are needed after about 4 months when neonatal iron stores have been depleted. Iron prophylaxis from the period of 4 months in term infants could improve iron stores and prevent occurrence of iron deficiency anaemia. $^{2}$

Average of $0.8 \mathrm{mg}$ of iron must be absorbed each day during the first 15 years of life. A small additional amount is necessary to balance normal losses of iron by shedding of cells. It is therefore necessary to absorb approximately $1 \mathrm{mg}$ daily to maintain positive iron balance in childhood. Because $<10 \%$ of dietary iron usually is absorbed, a dietary intake of 8 - $10 \mathrm{mg}$ of iron daily is necessary to maintain iron levels. ${ }^{4}$ 
During infancy when growth is most rapid, an approximately $1 \mathrm{mg} / \mathrm{L}$ of iron in bovine and breast milk makes it difficult to maintain body iron. Breast fed infants have an advantage, because they absorb iron 2 - 3 times more efficiently than infants fed on bovine milk. ${ }^{2}$

In India, prevalence of anaemia among children aged 6 months to 59 months based on NFHS-3 (National Family Health Survey) data was 6 - 8 months 79.9\%, 9 - 11 months $81.7 \%$ and $12-17$ months $84.5 \%$. $^{2}$ So we planned to study with the objective, what is the effect of iron prophylaxis in term infants from four-to-six months of age in preventing iron deficiency anaemia at one year of age?

\section{MATERIALS AND METHODS}

The study was conducted at Well Baby Clinic, in a Tertiary Level Hospital in South India with permission from Hospital Ethical Committee and with necessary consents. It was an experimental study done in a period of one year from February 2015 to July 2016. Study included term infants in the age group of 4-to- 6 months without anaemia, i.e. $\mathrm{Hb} 11$ or more and excluded babies who are preterm less than $1500 \mathrm{~g}$ birth weight, c/c systemic illness and haemopoietic disorders. All the eligible infants selected for the study were divided into 2 groups. Infants were selected alternatively; first infant came with the eligible criteria put on iron supplementation group, next infant in the non-iron supplement (control) group and so on. Total 44 infants enrolled with 22 in each group. Information about history, examination and anthropometry were entered in proforma. One group was given iron syrup (elemental iron as colloidal iron) at $2 \mathrm{mg} / \mathrm{kg} / \mathrm{day}$ along with vitamin D3 drops as per IAP recommendation; second group only vitamin D3.

Both the groups were asked to report every 3 months. They were assessed by clinical examination and growth parameters. During followup, enquiry was made about iron compliance. At the end that is by one year of age, all infants were reassessed and repeated haemoglobin level. If final $\mathrm{Hb}$ level was less than $11 \mathrm{~g} \%$, detailed evaluation for anaemia, with PCV, MCV, MCH, MCHC, Peripheral Smear, Retic Count, Serum Ferritin and Stool occult blood was also done.

These results were entered into pre-designed proforma and statistically analysed using SPSS-19 software by chisquare test, independent sample test and paired ' $t$ ' test.

\section{RESULTS}

Out of 22 infants in iron supplemented group, 14 were males and 8 females. Out of 22 infants in the control group, 13 were males and 9 females.

Baseline weight, length and haemoglobin levels of both groups are given in Table 1. Distribution of anaemia at the end of study in both groups are given in Table 2. Comparison of changes in growth parameters (weight and height) and haemoglobin levels in both groups at the end of study were noted in Table 3.

Haematological parameters in anaemic infants in both iron group and control group were as follows. Mean of PCV in iron group was 29.740 and in control group was 29.944. P value was more than 0.05 , which was not statistically significant. Mean of MCV in iron group was 76.000 and in control group was 73.661. P value was more than 0.05 , which was not statistically significant. Mean of MCH in iron group was 26.260 and in the control group was 25.250 . P value was more than 0.05 , which was not statistically significant. Mean $\mathrm{MCHC}$ in the iron group given was 30.7 and that of the control group was 30.976 . P value was more than 0.05 , which was not statistically significant.

Mean Ferritin values for those babies with anaemia at one year in the iron group and the control group was 106.60 and 45.91 respectively. In both the groups p value was less than 0.05 , which was statistically significant.

Peripheral smear of the anaemic infants in both the groups was done at the end of the study. In the iron group, out of 5 infants, 3 of them were found to have microcytic hypochromic anaemia and 2 infants had normocytic hypochromic anaemia. In the control group, out of 16 anaemic infants, all of them were found to have microcytic hypochromic picture. $\mathrm{P}$ value was less than 0.05 and found to be statistically significant.

\begin{tabular}{|c|c|c|c|c|c|}
\hline Parameter & Group & No. & Mean & SD/SE* & P value \\
\hline \multirow{2}{*}{ Age } & Iron & 22 & 4.559 & 0.3594 & 0.598 \\
\cline { 2 - 6 } & Control & 22 & 4.500 & 0.3780 & 0.598 \\
\hline \multirow{2}{*}{ Weight } & Iron & 22 & 5.968 & 0.0851 & 0.784 \\
\cline { 2 - 6 } & Control & 22 & 5.995 & 0.0499 & 0.784 \\
\hline \multirow{2}{*}{ Length } & Iron & 22 & 61.909 & 0.3200 & 0.017 \\
\cline { 2 - 6 } & Control & 22 & 60.886 & 0.2589 & 0.017 \\
\hline \multirow{2}{*}{ Haemoglobin } & Iron & 22 & 11.23 & 0.056 & 0.066 \\
\cline { 2 - 6 } & Control & 22 & 11.11 & 0.021 & 0.070 \\
\hline
\end{tabular}

Table 1. Distribution of Baseline Parameters

${ }^{*} \mathrm{SD}=$ Standard Deviation, $\mathrm{SE}=$ Standard Error

\begin{tabular}{|c|c|c|c|}
\hline Group & No. Anaemic & No. Not Anaemic & P value \\
\hline Iron & $5(22.7 \%)$ & $17(77.3 \%)$ & \\
\hline Control & $16(72.7 \%)$ & $6(27.3 \%)$ & 0.001 \\
\hline Total & $21(47.7 \%)$ & $23(52.3 \%)$ & \\
\hline \multicolumn{4}{|c|}{ Table 2. Distribution of Anaemia } \\
\hline
\end{tabular}

\begin{tabular}{|c|c|c|c|c|c|}
\hline Parameter & Group & No & Mean & SE & P value \\
\hline \multirow{2}{*}{ Weight } & iron & 22 & 3.1209 & 0.1407 & \\
\cline { 2 - 6 } & Control & 22 & 2.4159 & 0.1819 & 0.004 \\
\hline \multirow{2}{*}{ Length } & iron & 22 & 12.250 & 0.3082 & \\
\cline { 2 - 6 } & Control & 22 & 12.318 & 0.4334 & 0.899 \\
\hline \multirow{2}{*}{ Haemoglobin } & Iron & 22 & -0.0591 & 0.17736 & \\
\cline { 2 - 6 } & Control & 22 & -0.8409 & 0.21082 & 0.007 \\
\hline \multicolumn{6}{|c|}{ Table 3. Comparison of Changes in } \\
Weight/Length/Haemoglobin \\
\hline
\end{tabular}

\section{DISCUSSION}

The study was conducted with an aim to determine whether Iron prophylaxis will prevent iron deficiency anaemia in term infants. Among 44 infants $52.27 \%$ were males and $47.73 \%$ were females, slight male predominance. There is no statistically significant difference in the baseline, age, weight and haemoglobin of the infants in the two groups as indicated by $\mathrm{P}$ value. Thus, the two groups are comparable except for length.

Among 44 infants, proportion of anaemia (after the study) among iron supplemented group was found to be $22.7 \%$ compared to the control group which was $72.7 \%$. The difference in proportion was found to be statistically significant with $\mathrm{p}$ value of 0.001 . Hence, iron prophylaxis has 
a significant role in preventing anaemia. This result was comparable with the study done by Domellof et al, 6 that showed similar results as follows: iron deficiency anaemia was found to be $29 \%$ in placebo group against $9 \%$ in iron supplemented group. $\mathrm{P}$ value was 0.002 . Iron supplementation significantly reduces iron deficiency anaemia in breast-fed infants.

The mean difference of haemoglobin value at the end of the study between the iron given and control group was .0591 and -.8409. The independent sample test value was 2.838 and $p$ value was less than 0.05 , found to be statistically significant. This study shows that there is no significant fall in haemoglobin in iron given group as compared to control group. This result was comparable with study done by Agarwal et al, which shows that the change in haemoglobin status in iron supplemented group is better compared to placebo. ${ }^{1}$

The mean of weight difference between supplemented group and control group was 3.1209 and 2.4159. The independent sample test value was 3.066 and $p$ value was less than 0.05 , found to be statistically significant. Thus, this study shows significant weight gain in infants of Iron group as compared to Control group. So it is proved that iron supplementation improves weight status in infants. This is supported by other studies also.7,8,9,10

The mean difference of length between iron group and control group was 12.2500 and 12.3182. The independent sample test value was -.128 and $p$ value was 0.899 , found to be statistically insignificant. There is no significant difference of length in both groups.

The haematological parameters - MCV, MCH and MCHC were not significantly different among infants with anaemia at one year, both in iron and control groups. This observation was not comparable with the study done by Friel et al,7 which showed higher MCV and Haemoglobin values in iron supplemented group as compared to placebo group. But the serum ferritin level was at higher side in iron supplemented infants. All anaemic children in the control group were microcytic hypochromic in peripheral smear.

\section{CONCLUSION}

So we conclude from the study that prophylactic iron supplementation from 4 to 6 months of age onwards will prevent iron deficiency anaemia, improves haemoglobin level and also help adequate weight gain.

Iron deficiency anaemia is causally associated with developmental delay and with poor growth, both of which are reversible with treatment, at least when treatment is offered early in childhood.7,8,9,10 We would therefore advocate an approach which combines primary prevention and screening, particularly in the infants between 4 months and 2 years of age. Iron deficiency can impair immunity, mental and motor development, cognition, behaviour and performance in all stages of life.4,11,12 Iron prophylaxis from four-to-six months of age, in term infants, could improve iron stores and prevent the occurrence of iron deficiency anaemia, which will go a long way in preventing this extremely common morbidity in the community.

\section{REFERENCES}

[1] Aggarwal D, Sachdev HPS, Nagpal J, et al. Haematological effect of iron supplementation in breastfed term low birth weight infants. Arch Dis Childhood 2005;90(1):26-9.

[2] NFHS-3-chapter10-Nutrition and Anaemia. 2014. http://hetv.org/india/nfhs/nfhs3/NFHS-3-Chapter10Nutrition and anaemia.pdf

[3] National-iron-plus-Initiative guidelines-for control of IDA. 2015. http://WWW.Unicef.org/india/10.National iron plus initiative guidelines for control of IDA.

[4] Sills R. Iron deficiency anemia. In: Kliegman, Stanton, StGeme, et al. eds. Nelson textbook of pediatrics. $1^{\text {st }}$ SouthAsian edn. New Delhi: Reed Elsevier India 2016:2323-6.

[5] Nagpal J, Sachdev HP, Singh T, et al. A randomized placebo controlled trail of iron supplementation in breast fed young infants initiated on complementary feeding: Effect on haematological status. J Health popul Nutr 2004;22(2):203-11.

[6] Domellöf $\mathrm{M}$, Cohen RJ, Dewey $\mathrm{KG}$, et al. Iron supplementation of breast fed Honduran and Swedish infants from 4 to 9 month of age. J Pediatr 2001;138(5):679-87.

[7] Friel JK, Aziz K, Andrews WL, Harding SV, et al. A double-masked, randomized control trial of iron supplementation in early infancy in healthy term breast-fed infants. J Pediatr 2003;143(5):582-6.

[8] Ziegler EE, Nelson SE, Jeter JM. Iron supplementation of breast fed infant from an early age. Am J Clin Nutr 2009;89(2):525-32.

[9] Lanzkowsky P. Iron-Deficiency Anemia. In: Philip lanzkowsky. edr. Text book pediatric hematology and oncology. 4th edn. Amsterdam: Academic Press 2005: 31-46.

[10] Miller V, Swaney S, Deinard A. Impact of the WIC program on the iron status of infants. Pediatrics 1985;75(1):100-5.

[11] Lozoff B, Jimenez E, Smith JB. Double burden of iron deficiency in infancy and socio economic status: a longitudinal analysis of cognitive test scores to age 19 years. Arch Pediatr Adolesc Med 2006;160(11):110813.

[12] Bruner AB, Joffe A, Duggan AK, et al. Randomized study of cognitive effects of iron supplementation in non-anemic iron-deficient adolescent girls. Lancet 1996;348(9033):992-6. 